\title{
Sudden Death in a Patient with Pulmonary Veno-occlusive Disease (PVOD) and Severe Pulmonary Hypertension
}

\author{
Minako Saito ${ }^{1}$, Nobuharu Ohshima ${ }^{2}$, Hirotoshi Matsui ${ }^{1}$, Akira Hebisawa $^{3}$ and Ken Ohta $^{2}$
}

\begin{abstract}
A 58-year-old woman was referred to our hospital with a chief complaint of exertional dyspnea. Bronchoscopy failed to establish a diagnosis, and the patient subsequently died suddenly due to respiratory insufficiency because of advanced pulmonary hypertension (PH). The pathological diagnosis at autopsy was pulmonary veno-occlusive disease (PVOD). PVOD is difficult to diagnose antemortem and has a poor prognosis. Lung transplantation is the only curative treatment for PVOD.
\end{abstract}

Key words: pulmonary veno-occlusive disease, pulmonary hypertension, exertional dyspnea, sudden death

(Intern Med 56: 2025-2031, 2017)

(DOI: 10.2169/internalmedicine.56.7869)

\section{Introduction}

Pulmonary veno-occlusive disease (PVOD) presents with severe and progressive exertional hypoxemia and pulmonary hypertension $(\mathrm{PH})$, resulting in a very poor prognosis.

In the 2015 European Society of Cardiology (ESC)/European Respiratory Society (ERS) guidelines, PVOD/pulmonary capillary hemangiomatosis $(\mathrm{PCH})$ have been given the subgroup designation of group 1, because they differ greatly from the pulmonary arterial hypertension $(\mathrm{PAH})$; the guidelines have proposed the further classification of $\mathrm{PVOD} / \mathrm{PCH}$ into idiopathic, heritable, drug-, toxins-, and radiationinduced and associated forms (1). When the drugs used in the treatment of PAH are given to PVOD patients, they dilate the pulmonary arteries, increase the capillary hydrostatic pressure, and are likely to worsen pulmonary edema. Thus, lung transplantation is the only curative treatment for PVOD. We herein present the case of a patient with PVOD in whom transbronchial lung biopsy (TBLB) failed to establish a diagnosis. The patient's PH progressed over a period of several months and did not improve with drug treatment. The diagnosis of PVOD was first made at autopsy.

\begin{abstract}
Case Report
A 58-year-old woman visited her primary physician with a chief complaint of exertional dyspnea that began 2 months before hospitalization. Chest radiography showed a reticulated pattern in both lower lung fields and bilateral hilar lymphadenopathy. The patient was referred to our hospital and admitted for further evaluation.

She was a current smoker with 60-pack-year smoking history. The findings on admission were as follows: New York Heart Association (NYHA) Class III, body temperature, $36^{\circ} \mathrm{C}$; blood pressure, $118 / 72 \mathrm{mmHg}$; pulse rate, $78 / \mathrm{min}$; respiratory rate, 28/min; and $\mathrm{SpO}_{2}, 88 \%$ (room air).

The laboratory tests on admission (Table 1) showed mild elevations in the patient's lactate dehydrogenase (LDH), surfactant protein-D (SP-D), carcinoembryonic antigen (CEA), and rheumatoid factor (RF) levels. The patient was negative for all connective tissue disease (CTD) markers. An arterial blood gas analysis showed hypoxemia and respiratory alkalemia. Pulmonary function tests showed a mild restrictive disorder (vital capacity, 76.9\%), whereas the diffusing capacity of the lung for carbon monoxide (DLCO), as determined by the steady state method, was reduced to $33.5 \%$ of the predicted value. An electrocardiogram showed peaked $\mathrm{p}$
\end{abstract}

\footnotetext{
${ }^{1}$ Center for Pulmonary Diseases, National Hospital Organization Tokyo National Hospital, Japan, ${ }^{2}$ Asthma and Allergy Center, National Hospital Organization Tokyo National Hospital, Japan and ${ }^{3}$ Department of Clinical Research, National Hospital Organization Tokyo National Hospital, Japan

Received for publication June 16, 2016; Accepted for publication October 30, 2016

Correspondence to Dr. Nobuharu Ohshima, ohshima-in@ tokyo-hosp.jp
} 
Table 1. Laboratory Data on the First Admission.

\begin{tabular}{|c|c|c|c|c|c|}
\hline \multicolumn{2}{|c|}{ Hematology } & \multicolumn{2}{|l|}{ Serology } & \multicolumn{2}{|c|}{ Arterial blood gas (room air) } \\
\hline WBC & $8,300 / \mu \mathrm{L}$ & CRP & $0.78 \mathrm{mg} / \mathrm{dL}$ & $\mathrm{pH}$ & 7.442 \\
\hline Neut & $58 \%$ & $\operatorname{IgG}$ & $2,215 \mathrm{mg} / \mathrm{dL}$ & $\mathrm{pCO}_{2}$ & $29.6 \mathrm{mmHg}$ \\
\hline Lymp & $37 \%$ & $\operatorname{IgA}$ & $407 \mathrm{mg} / \mathrm{dL}$ & $\mathrm{pO}_{2}$ & $48.8 \mathrm{mmHg}$ \\
\hline Eosi & $3 \%$ & $\operatorname{IgM}$ & $91 \mathrm{mg} / \mathrm{dL}$ & $\mathrm{HCO}_{3}^{-}$ & $19.7 \mathrm{mmol} / \mathrm{L}$ \\
\hline $\mathrm{RBC}$ & $447 \times 10^{4} / \mu \mathrm{L}$ & $\operatorname{IgE}$ & $164 \mathrm{mg} / \mathrm{dL}$ & $\mathrm{BE}$ & $-3.1 \mathrm{mmol} / \mathrm{L}$ \\
\hline $\mathrm{Hb}$ & $14 \mathrm{~g} / \mathrm{dL}$ & Ferritin & $154 \mathrm{ng} / \mathrm{mL}$ & & \\
\hline \multirow[t]{2}{*}{ Plt } & $27.7 \times 10^{4} / \mu \mathrm{L}$ & KL-6 & $371 \mathrm{U} / \mathrm{mL}$ & & \\
\hline & & SP-D & $293 \mathrm{ng} / \mathrm{mL}$ & & \\
\hline \multicolumn{2}{|c|}{ Biochemistry } & IL2R & $410 \mathrm{U} / \mathrm{mL}$ & & \\
\hline TP & $7.9 \mathrm{~g} / \mathrm{dL}$ & $\mathrm{ACE}$ & $8.7 \mathrm{IU} / \mathrm{mL}$ & & \\
\hline $\mathrm{Alb}$ & $4 \mathrm{~g} / \mathrm{dL}$ & $\beta \mathrm{D}$ glucan & $11.8 \mathrm{pg} / \mathrm{mL}$ & & \\
\hline LDH & $255 \mathrm{IU} / \mathrm{L}$ & CEA & $8.9 \mathrm{ng} / \mathrm{mL}$ & & \\
\hline AST & $26 \mathrm{IU} / \mathrm{L}$ & $\mathrm{RF}$ & $35 \mathrm{IU} / \mathrm{mL}$ & & \\
\hline ALT & $33 \mathrm{IU} / \mathrm{L}$ & ANA & $<\times 40$ & & \\
\hline$\gamma$-GTP & $37 \mathrm{IU} / \mathrm{L}$ & Anti-RNP Ab & $(-)$ & & \\
\hline ALP & $235 \mathrm{IU} / \mathrm{L}$ & Anti-Scl70 Ab & $(-)$ & & \\
\hline Cre & $0.77 \mathrm{mg} / \mathrm{dL}$ & Anti-centromere $\mathrm{Ab}$ & $(-)$ & & \\
\hline $\mathrm{Na}$ & $142 \mathrm{mEq} / \mathrm{L}$ & Anti-SSA Ab & $(-)$ & & \\
\hline K & $4.1 \mathrm{mEq} / \mathrm{L}$ & Anti-SSB Ab & $(-)$ & & \\
\hline \multirow[t]{2}{*}{$\mathrm{Cl}$} & $105 \mathrm{mEq} / \mathrm{L}$ & PR3-ANCA & $(-)$ & & \\
\hline & & MPO-ANCA & $(-)$ & & \\
\hline
\end{tabular}

LDH: Lactate Dehydrogenase, SP-D: surfactant protein D, IL2R: interleukin-2 receptor, ACE: angiotensin converting enzyme, $\beta$ D glucan: $(1 \rightarrow 3) \beta$-D-glucan, CEA: carcinoembryonic antigen, RF: rheumatoid factor, ANA: anti nuclear antibodies, Anti-RNP Ab: anti ribonucleoprotein antibody, Anti-Scl70 Ab: anti scleroderma antibody, Anti-centromere Ab: anti centromere antibody, Anti-SSA Ab: anti SS-A antibody, Anti-SSB Ab: anti SS-B antibody, PR3-ANCA: proteinase-3 anti neutrophil cytoplasmic antibody, MPO-ANCA: myeloperoxidase anti neutrophil cytoplasmic antibody

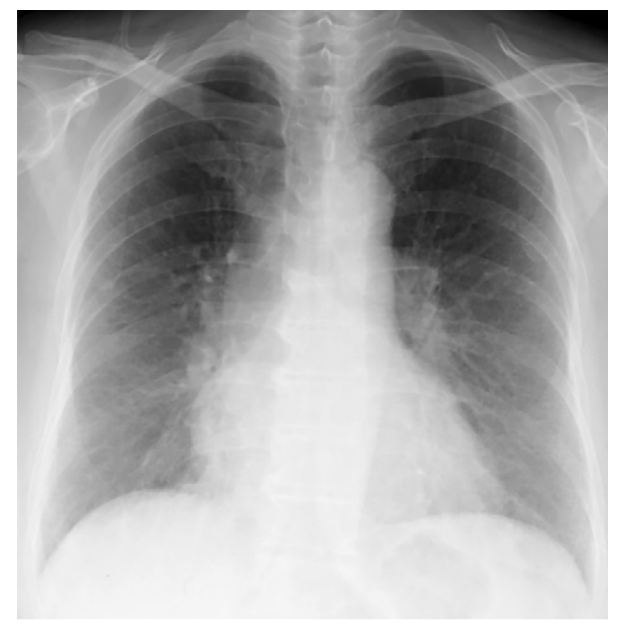

Figure 1. Chest radiography on initial admission. Reticular patterns were observed in both lower lung fields, along with bilateral hilar adenopathy, and right atrial enlargement.

waves in leads II, aVF, and V1. Echocardiography showed that the left ventricular systolic function was maintained, while the right ventricular systolic pressure (RVSP) and tricuspid regurgitation pressure gradient (TRPG) were mildly elevated at $52.0 \mathrm{mmHg}, 42.0 \mathrm{mmHg}$, respectively and the right ventricle was enlarged. We did not perform a 6-minute walk test. Chest radiography on admission (Fig. 1) showed a reticular pattern in both lower lung fields, bilateral hilar ade- nopathy, and right atrial enlargement. Chest computed tomography (CT) on admission (Fig. 2) showed bilateral hilar and mediastinal lymphadenopathy, ground glass opacities with lobular septal thickening, predominantly in both lower lung fields, and pulmonary artery enlargement.

Bronchoscopy was performed on hospital Day 5. TBLB of the right lower, middle, and upper lobes was performed. The histopathology was nonspecific, showing only alveolar septal fibrosis and small round cell infiltration, leading to a pathological diagnosis of chronic interstitial pneumonitis. The TBLB findings were again reviewed after the diagnosis was made. Although alveolar septal fibrosis and the fibrous obliteration of the small veins and venules were present (Fig. 3), these changes were slight and could not lead to the correct diagnosis. A thoracoscopic lung biopsy was contraindicated because of the high risk of morbidity and mortality. She was discharged from hospital on Day 17 with home oxygen therapy $(1.5 \mathrm{~L} / \mathrm{min}$ at rest and $3 \mathrm{~L} / \mathrm{min}$ during exertion) to maintain $\mathrm{SpO}_{2}$ level of $>90 \%$. We continued the prescription of furosemide $(20 \mathrm{mg} /$ day $)$ and enalapril $(2.5 \mathrm{mg} /$ day), which had been prescribed by her primary care doctor before admission.

However, the patient's symptoms did not improve. At approximately 6 months after her discharge from hospital, her dyspnea worsened due to a cold and she revisited our hospital. Since her $\mathrm{SpO}_{2}$ was $80-85 \%$ with $2 \mathrm{~L} / \mathrm{min}$ of oxygen by cannula, the patient was readmitted to our hospital. 


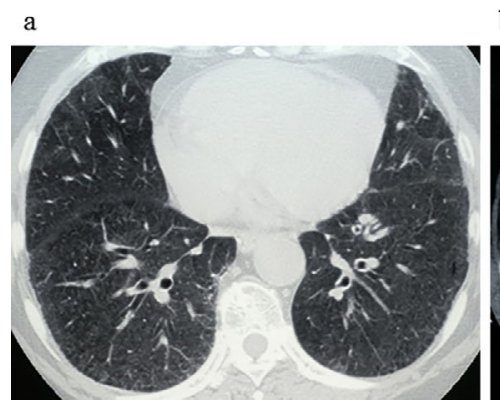

b

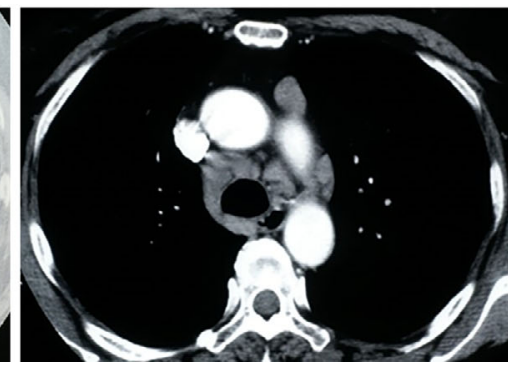

C

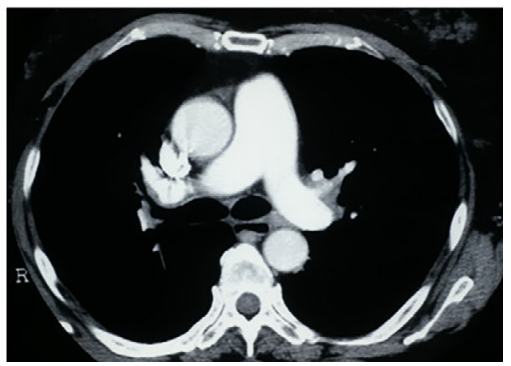

Figure 2. a: Chest CT on initial admission (lung fields). Ground glass opacities with lobular septal thickening were predominant in both lower lobes. b: Chest CT on initial admission (mediastinum). Mediastinal lymphadenopathy was observed. c: Chest CT on initial admission (mediastinum). Pulmonary artery enlargement was observed.

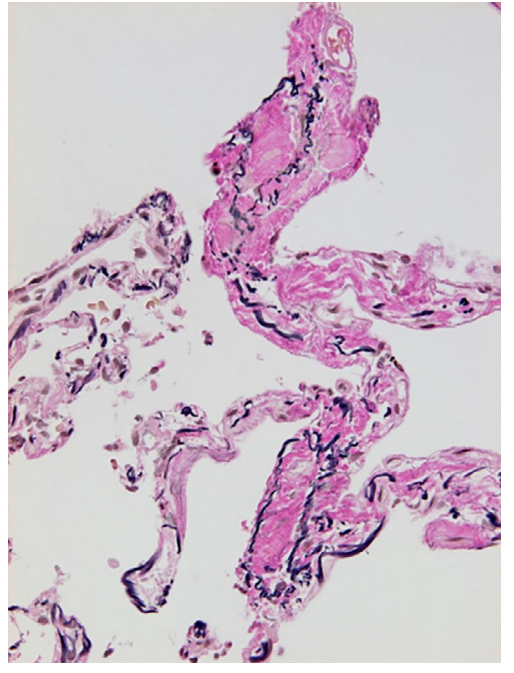

Figure 3. Histopathology at TBLB (EVG staining $\times 100)$. Fibrous obliteration of the small veins and venules was observed.

Laboratory tests showed an elevated LDH level, severe hypoxemia and the deterioration of her respiratory alkalemia (Table 2). An electrocardiogram showed peaked $\mathrm{p}$ waves in leads II, aVF, and V1, a deep S wave in lead I, and a negative $\mathrm{T}$ wave in lead III, all of which were consistent with right heart overload. Echocardiography showed a decreased left ventricular systolic function with an ejection fraction (EF) of 50\%. Her RVSP and TRPG values were further elevated to $72.0 \mathrm{mmHg}$ and $60.0 \mathrm{mmHg}$, respectively, and right ventricular enlargement and ventricular septal flattening were observed. In addition to a reticular pattern in both lower lung fields and bilateral hilar lymphadenopathy, chest radiography also showed right atrial enlargement and a right pleural effusion (Fig. 4). Chest CT revealed an increase in bilateral hilar and mediastinal lymphadenopathy, a small amount of right pleural effusion, a severely enlarged pulmonary artery, increased pulmonary vascular markings, and a reticular granular pattern, predominantly in the lower lung fields (Fig. 5). We could not perform pulmonary function tests or a 6-minute walk test.

Based on the marked hypoxemia, the imaging findings of a reticular pattern with lobular septal thickening, and the
TBLB findings during her previous hospitalization, an acute exacerbation of interstitial pneumonitis was initially considered. Steroid pulse therapy (methylprednisolone $[1 \mathrm{~g}$ for 3 days]) was started on admission. Her $\mathrm{SpO}_{2}$ was maintained at about $95 \%$ with an oxygen cannula $(2 \mathrm{~L} / \mathrm{min})$, and there was a slight temporary improvement in her exertional dyspnea. However, on hospital Day 14, the patient's dyspnea and oxygenation worsened, and $12 \mathrm{~L} / \mathrm{min}$ of $50 \%$ oxygen by venturi mask was required to achieve an $\mathrm{SpO}_{2}$ of $95 \%$. Thus, a second course of steroid pulse therapy was administered. In addition, her brain natriuretic peptide (BNP) was elevated to $827 \mathrm{pg} / \mathrm{mL}$, pleural effusion developed, and echocardiography showed an increase in TRPG to 62.1 mmHg (Fig. 6a). Diuretics were added to treat the patient's worsening right heart failure.

Her respiratory status improved with an $\mathrm{SpO}_{2}$ level of $\geq$ $90 \%$ on $6 \mathrm{~L} / \mathrm{min}$ of oxygen by cannula. However, the patient developed severe lower leg edema, and echocardiography on hospital Day 42 showed a further increase in TRPG to $72.9 \mathrm{mmHg}$ (Fig. 6b). For the PH with right heart failure, beraprost sodium $(120 \mu \mathrm{g} / \mathrm{day})$ was started on hospital Day 43. On hospital Day 48, however, her respiratory status worsened again and required $8 \mathrm{~L} / \mathrm{min}$ of oxygen by reservoir mask. Chest radiography showed an increased reticular pattern in both lungs, again suggesting an acute exacerbation of interstitial pneumonitis. A third course of steroid pulse therapy was given, and then prednisolone $(30 \mathrm{mg})$ was initiated as an after-treatment. Nevertheless, the respiratory insufficiency progressed, and the patient died suddenly on hospital Day 59 (Diagram: Fig. 7).

Consent was obtained from the patient's family for an autopsy. The left lung weighed $485 \mathrm{~g}$, and the right lung weighed $445 \mathrm{~g}$. A histopathological examination showed hyaline fibrosis of the alveolar septa and fibrous obliteration and concentric intimal thickening of the venules (Fig. 8a and b). Heath-Edwards grade II (2) medial hypertrophy of the pulmonary artery was present, but plexiform lesions were not observed (Fig. 8c). There were also dilated, multi-layered capillaries, hemorrhages in the alveolar spaces and alveolar septum, and areas of hemosiderosis (Fig. 8d). The mediastinal lymph nodes were enlarged to 40 
Table 2. Laboratory Data on the Second Admission.

\begin{tabular}{|c|c|c|c|c|c|}
\hline \multicolumn{2}{|c|}{ Hematology } & \multicolumn{2}{|l|}{ Serology } & \multicolumn{2}{|c|}{ Arterial blood gas (nasal canula 2L) } \\
\hline WBC & $9,900 / \mu \mathrm{L}$ & CRP & $0.6 \mathrm{mg} / \mathrm{dL}$ & $\mathrm{pH}$ & 7.482 \\
\hline Neut & $58 \%$ & IgG & $1,833 \mathrm{mg} / \mathrm{dL}$ & $\mathrm{pCO}_{2}$ & $22.4 \mathrm{mmHg}$ \\
\hline Lymp & $38.4 \%$ & $\operatorname{IgA}$ & $357 \mathrm{mg} / \mathrm{dL}$ & $\mathrm{pO}_{2}$ & $47.7 \mathrm{mmHg}$ \\
\hline Eosi & $0.1 \%$ & $\operatorname{IgM}$ & $62 \mathrm{mg} / \mathrm{dL}$ & $\mathrm{HCO}_{3}^{-}$ & $16.4 \mathrm{mmol} / \mathrm{L}$ \\
\hline $\mathrm{RBC}$ & $\times 10^{4} / \mu \mathrm{L}$ & $\operatorname{IgE}$ & $200 \mathrm{mg} / \mathrm{dL}$ & Base excess & $-5.2 \mathrm{mmol} / \mathrm{L}$ \\
\hline $\mathrm{Hb}$ & $13.4 \mathrm{~g} / \mathrm{dL}$ & Ferritin & $311 \mathrm{ng} / \mathrm{mL}$ & & \\
\hline \multirow[t]{2}{*}{ Plt } & $11.5 \times 10^{4} / \mu \mathrm{L}$ & KL-6 & $380 \mathrm{U} / \mathrm{mL}$ & & \\
\hline & & SP-D & $311 \mathrm{ng} / \mathrm{mL}$ & & \\
\hline \multicolumn{2}{|c|}{ Biochemistry } & IL2R & $555 \mathrm{U} / \mathrm{mL}$ & & \\
\hline TP & $7.1 \mathrm{~g} / \mathrm{dL}$ & ACE & $6.8 \mathrm{IU} / \mathrm{L}$ & & \\
\hline $\mathrm{Alb}$ & $3.7 \mathrm{~g} / \mathrm{dL}$ & $\beta \mathrm{D}$ glucan & $<6.0 \mathrm{pg} / \mathrm{mL}$ & & \\
\hline LDH & $369 \mathrm{IU} / \mathrm{L}$ & CEA & $9.5 \mathrm{ng} / \mathrm{mL}$ & & \\
\hline AST & $33 \mathrm{IU} / \mathrm{L}$ & $\mathrm{RF}$ & $26 \mathrm{IU} / \mathrm{L}$ & & \\
\hline ALT & $26 \mathrm{IU} / \mathrm{L}$ & ANA & $<\times 40$ & & \\
\hline$\gamma$-GTP & $24 \mathrm{IU} / \mathrm{L}$ & Anti-RNP Ab & $(-)$ & & \\
\hline ALP & $223 \mathrm{IU} / \mathrm{L}$ & Anti-Scl70 Ab & $(-)$ & & \\
\hline Cre & $0.82 \mathrm{mg} / \mathrm{dL}$ & Anti-centromere $\mathrm{Ab}$ & $(-)$ & & \\
\hline $\mathrm{Na}$ & $133 \mathrm{mEq} / \mathrm{L}$ & Anti-SSA Ab & $(-)$ & & \\
\hline K & $4 \mathrm{mEq} / \mathrm{L}$ & Anti-SSB Ab & $(-)$ & & \\
\hline \multirow[t]{2}{*}{$\mathrm{Cl}$} & $100 \mathrm{mEq} / \mathrm{L}$ & PR3-ANCA & $(-)$ & & \\
\hline & & MPO-ANCA & $(-)$ & & \\
\hline
\end{tabular}

LDH: Lactate Dehydrogenase, SP-D: surfactant protein D, IL2R: interleukin-2 receptor, ACE: angiotensin converting enzyme, $\beta$ D glucan: $(1 \rightarrow 3) \beta$-D-glucan, CEA: carcinoembryonic antigen, RF: rheumatoid factor, ANA: anti nuclear antibodies, Anti-RNP Ab: anti ribonucleoprotein antibody, Anti-Scl70 Ab: anti scleroderma antibody, Anti-centromere Ab: anti centromere antibody, Anti-SSA Ab: anti SS-A antibody, Anti-SSB Ab: anti SS-B antibody, PR3-ANCA: proteinase-3 anti neutrophil cytoplasmic antibody, MPO-ANCA: myeloperoxidase anti neutrophil cytoplasmic antibody

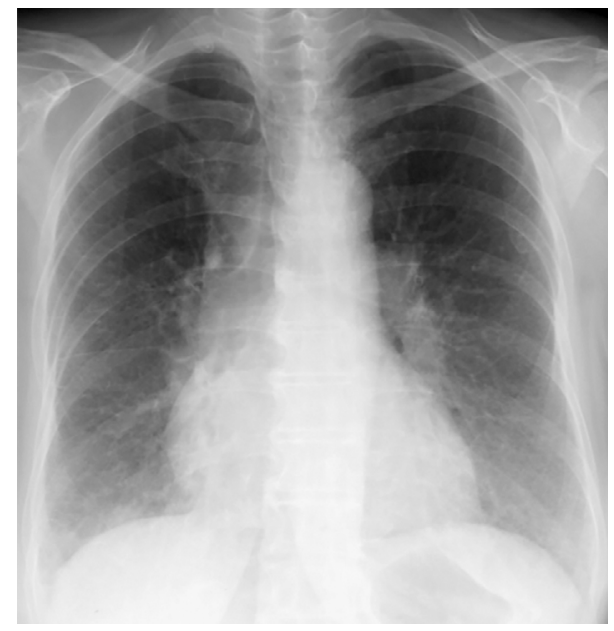

Figure 4. Chest radiography on readmission. Right atrial enlargement and right pleural effusion were observed in addition to a reticular pattern in both lower lung fields and bilateral hilar lymphadenopathy.

$\mathrm{mm} \times 35 \mathrm{~mm} \times 15 \mathrm{~mm}$, with enlarged lymph sinuses and histiocytic hemophagocytosis (Fig. 8e). A diagnosis of PVOD was made based on the clinical course and autopsy findings. We concluded that her cause of death was respiratory failure by progressive right heart failure.

\section{Discussion}

PVOD was first reported by Hora et al. (3) in 1934, and it was recognized as a separate disease entity by Heath et al. (4) in 1966. The exact prevalence of PVOD is unknown, but it is estimated to be 0.1-0.2 per one million population per year (5). Pathologically, the venules and small septal veins in PVOD are most often involved with the arterial and capillary components of the pulmonary vasculature, whereas plexiform lesions, a characteristic of PAH, are not found. In this case, the pathological features were compatible with PVOD. In terms of the clinical course, PVOD typically demonstrates a poor response to the vasodilator drugs used in PAH, resulting in severe pulmonary edema (6).

The etiology of PVOD is not completely understood, but associations with genetic factors, anticancer drugs such as mitomycin and bleomycin, bone marrow transplantation, radiation therapy, smoking, CTDs such as systemic lupus erythematosus (SLE) and rheumatoid arthritis (RA), and chronic hepatitis have been reported (6). The French PH network reported the genealogy of 13 PVOD families with heritable disease and demonstrated that biallelic mutations were present in eukaryotic translation initiation factor 2 alpha kinase 4 (EIF2AK4) (7). The French PH networks stated that these mutations were also identified in $9 \%$ of apparently sporadic cases of PVOD, when they offered genetic counselling and EIF2AK4 mutation screening to all patients with or without a family history (8). The present patient had no family history of PVOD, but these mutations might have been associated. In this case, the screening tests for CTD were all negative, and although smoking has been men- 


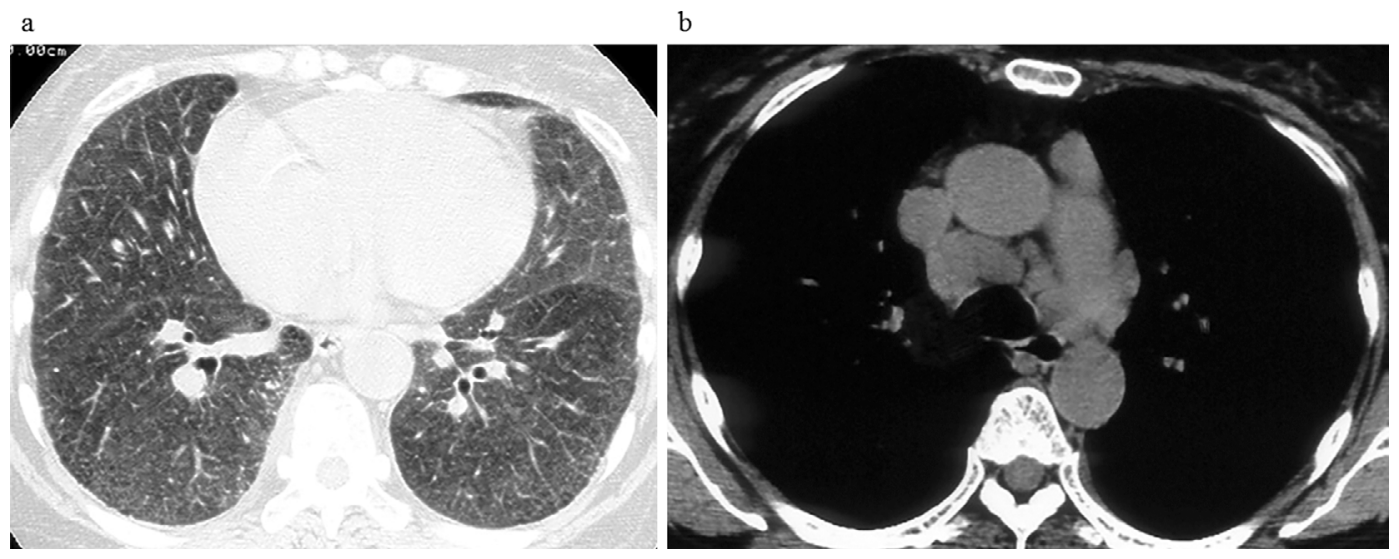

Figure 5. a: Chest CT on readmission (lung fields). An increase in the reticular granular pattern was observed, predominantly in both lower lobes, along with increased pulmonary vascular markings. b: Chest CT on readmission (mediastinum). Further enlargement of the mediastinal lymph nodes was observed.
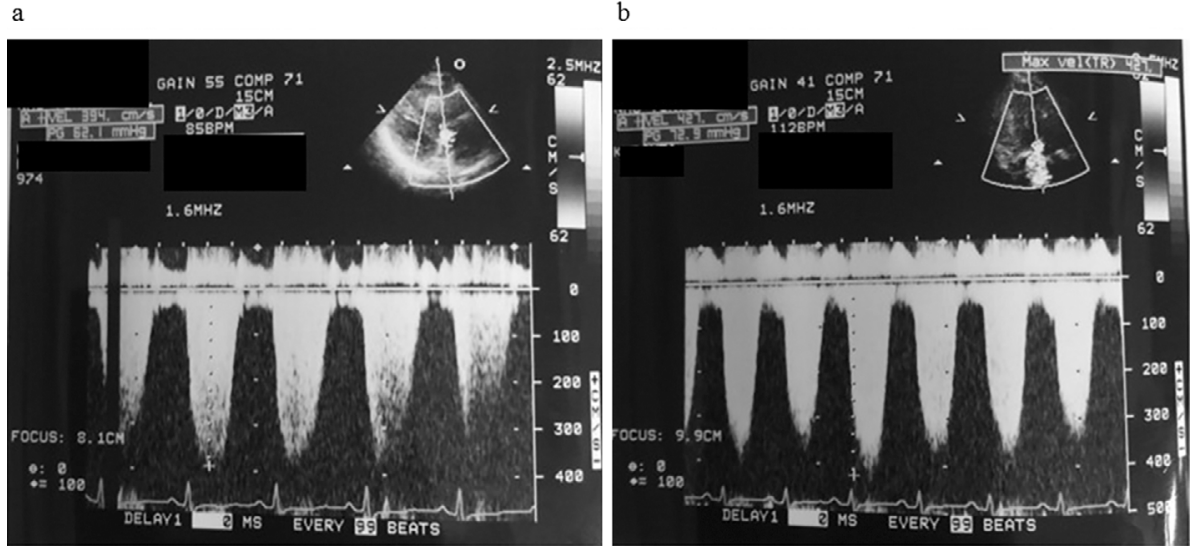

Figure 6. a: An echocardiographic image on day 19 of the second hospitalization. b: An echocardiographic image on day 41 of the second hospitalization.

The clinical course after readmission in a diagram

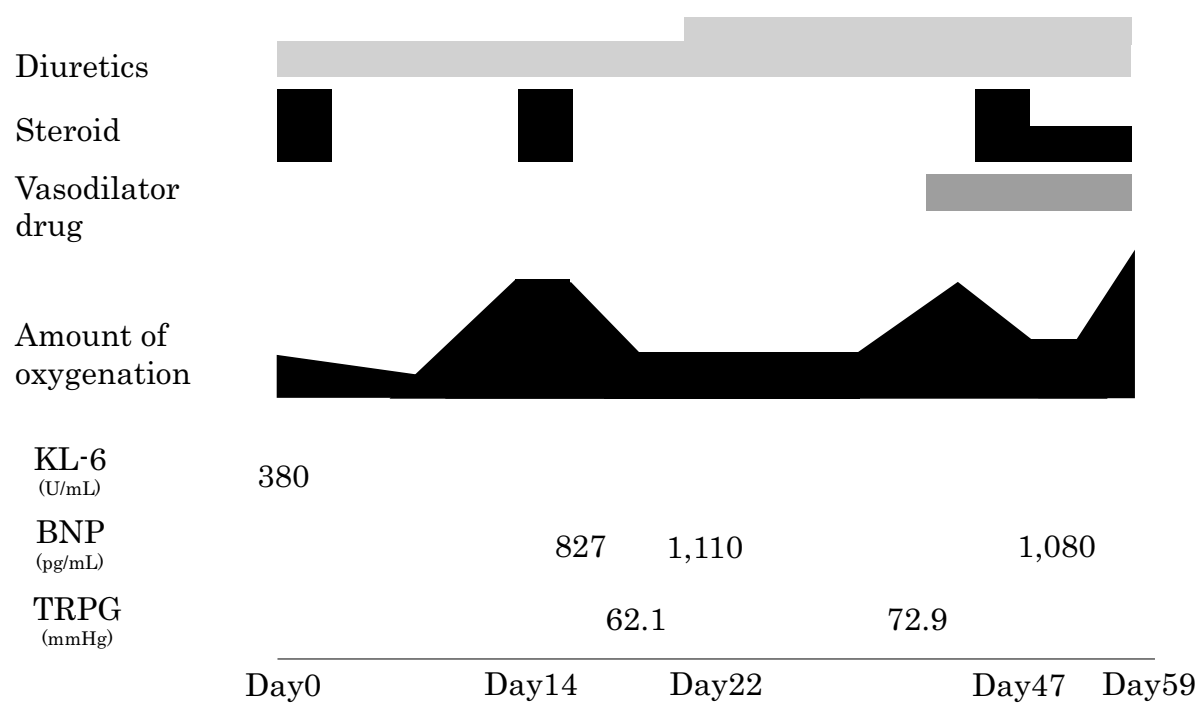

Figure 7. A diagram of the clinical course of the present case. 

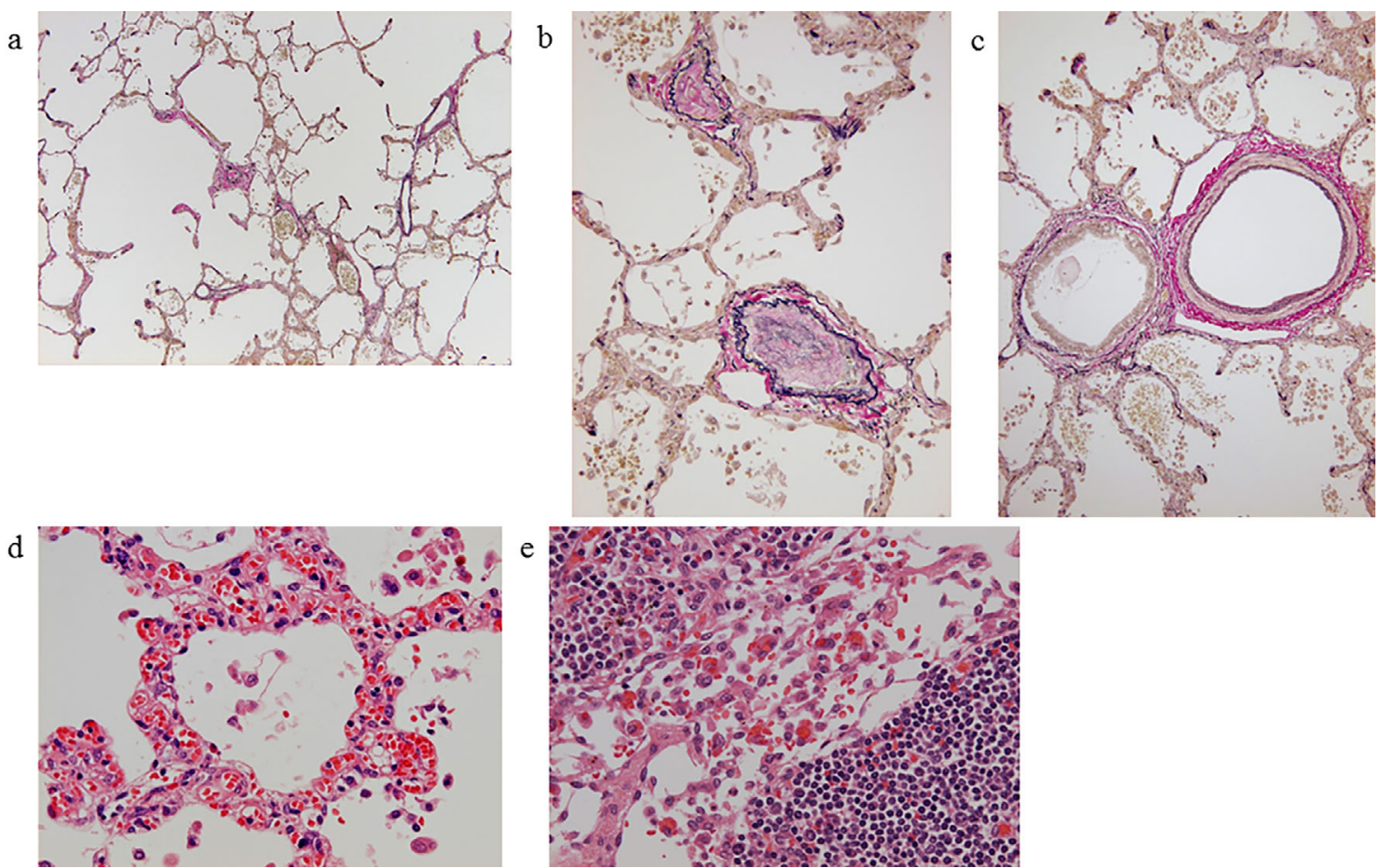

Figure 8. a: The histopathology at autopsy $($ EVG staining $\times 40)$. Hyaline fibrosis of the alveolar septum and fibrous obliteration of the small veins and venules were observed. $b$ : The histopathology at autopsy $($ EVG staining $\times \mathbf{1 0 0})$. Fibrous obliteration and narrowing due to concentric intimal thickening of the small veins and venules were observed. c: Histopathology at autopsy (EVG staining $\times 100)$. The histopathological examination revealed Heath-Edwards grade II and medial hypertrophy of the pulmonary artery without plexiform lesions. d: The histopathology at autopsy [Hematoxylin and Eosin $(H \& E)$ staining $\times 40]$. Dilated, multi-layered capillaries, hemorrhages in the alveolar spaces and alveolar septum, and areas of hemosiderosis were observed. e: The histopathology at autopsy $($ H\&E staining $\times 40)$. Enlarged mediastinal lymph nodes with enlarged lymph sinuses and histiocytic hemophagocytosis were observed.

tioned as a risk factor, there is no firm evidence.

An evaluation by right heart catheterization (RHC) is essential for the diagnosis of PH. However, in this case, because our institution had not yet completely arranged an RHC system, we could not perform a hemodynamic assessment.

A definitive diagnosis of PVOD requires a surgical lung biopsy, but because of the invasive risk of this procedure, few patients, including the present patient, are diagnosed with PVOD antemortem (6). Rabiller et al. (9) found that hemosiderin-laden macrophages were significantly increased in the bronchoalveolar lavage (BAL) fluid of PVOD patients, which meant that PVOD is associated with occult alveolar hemorrhage due to the presence of post-capillary block. The 2015/ESC/RES Guidelines of PH (1) state that BAL may be a useful diagnostic strategy for PVOD unless severe hypoxemia is present, while TBLB is no longer recommended in patients with severe $\mathrm{PH}$ due to the high risk of bleeding. However, in this case, we decided to give priority to TBLB. Because the initial diagnosis at the first hospitalization was interstitial pneumonia, we considered the severity of her PH to be mild, and thought that her respiratory status gradually deteriorated during bronchoscopy. When we reviewed the TBLB findings again, we found that we had missed slight pathological findings. These results indicate the difficulty of making an antemortem diagnosis of PVOD.

The present patient had various imaging findings, including ground glass opacities with lobular septal thickening, mediastinal lymphadenopathy, and centrilobular granular shadows, and these findings initially suggested sarcoidosis or hypersensitivity pneumonitis. Resten et al. (10) compared the chest CT findings in PVOD with those in idiopathic PAH. They reported that ground glass opacities, lobular septal thickening, and mediastinal lymphadenopathy were significantly more frequent in PVOD, and that the ground glass opacities more often had a centrilobular pattern than a panlobular pattern. These findings reflect interlobular septal edema followed by fibrosis and the lymphatic dilation associated with pulmonary venous occlusion (11). The imaging findings in the present patient was a characteristic of PVOD.

The prognosis of PVOD is very poor, with a one-year mortality rate of $72 \%$ (12). Most patients die within 2 years after being diagnosed, and the prognosis is even poor in comparison to PAH (13). Lung transplantation is the only curative treatment (14), but the long average waiting time in Japan (889.6 days) (15), means that most patients with PVOD progress before they have the opportunity to undergo transplantation. With regard to drug treatment, when the 
vasodilator drugs that are used to treat idiopathic $\mathrm{PAH}$ are given to patients with PVOD, who have high pulmonary venous resistance, the pulmonary artery dilates, the capillary hydrostatic pressure rises, and pulmonary edema is likely to occur. Thus, the use of these drugs in PVOD is controversial (14).

Increasing the dose of diuretics could not control the rapidly progressing right heart failure in the present patient. U1timately, beraprost sodium, a prostaglandin I2 (PGI2) ana$\log$, was started. However, within a few days after starting the drug, the interstitial opacities increased and the patient's respiratory status worsened. Thus, the PGI2 drug may have actually worsened the patient's pulmonary edema.

Ogawa et al. (16) reported the results of initiating treatment with low-dose epoprostenol in PVOD patients who were already using diuretics or vasopressors. With careful management to achieve venodilation and reduce the hydrostatic pressure, it could eventually be increased to a mean maximum dose of $55.3 \pm 10.7 \mathrm{ng} / \mathrm{kg} / \mathrm{min}$. The NYHA class, 6-minute walking distance, and BNP levels improved. However, even though epoprostenol improved the exercise tolerance and increased the cardiac output, the pulmonary artery pressure and right atrial pressure were not reduced. Thus, the effectiveness is temporary and may be limited to shortterm treatment as a bridge until lung transplantation.

The present patient was not eligible for lung transplantation because she was over 55 years of age. However, we think we should have started beraprost sodium treatment at a low dose of $60 \mu \mathrm{g} / \mathrm{day}$, or chosen epoprostenol and slowly increased the dose because we would have been able to easily adjust the amount as it is administered by continuous infusion.

The 2015/ESC/RES Guidelines of PH (1), note that a highly probable diagnosis of PVOD can be made based on the combination of clinical suspicion, a physical examination, bronchoscopy and tradiological findings. In the present case, the initial diagnosis was interstitial pneumonitis such as sarcoidosis, hypersensitivity pneumonia, or idiopathic interstitial pneumonia because of the radiological findings and TBLB findings during the prior hospitalization. However, several points were not compatible; her clinical course was very aggressive, granulomas were not detected by TBLB, there was no uptake on Gallium scintigraphy, the patient was negative for Trichosporon asahii antibodies, and there was no history of exposure. On the other hand, the severe desaturation on exercise, the very low DLCO level, the characteristic radiological findings and the rapid progression of right heart failure were consistent with PVOD. When looking back, we should have suspected PVOD before the patient's second admission and have at least made an appropriate diagnostic approach to progressive right heart failure, especially RHC. It is very important to perform RHC to con- firm PH. For an early diagnosis, PVOD should always be considered in patients with these clinical features and imaging findings. PVOD is such a rare case and the clinical course of it is so progressive that it is very important for physicians to suspect it in the early phase by a noninvasive approach and to immediately refer patients who are eligible for lung transplantation.

The authors state that they have no Conflict of Interest (COI).

\section{References}

1. Galie N, Humbert M, Vachiery JL, et al. 2015 ESC/ERS Guidelines for the diagnosis and treatment of pulmonary hypertention. Eur Respir J 46: 903-975, 2015.

2. Heath D, Edwards J. The pathology of hypertensive pulmonary vascular disease. A description of six grades of structural changes in the pulmonary arteries with special references to congenital cardiac septal defects. Circulation 18: 533-537, 1958.

3. Hora J. Zur histologie der klinischen 'primaren pulmonalsklerose'. Frankf Z Pathol 47: 100, 1934.

4. Heath D, Segel N, Bishop J. Pulmonary veno-occlusive disease. Circulation 34: 242-248, 1966.

5. Mandel J, Mark EJ, Hales CA. Pulmonary veno-occlusive disease. Am J Respir Crit Care Med 162: 1964-1973, 2000.

6. David M, Dermot S, Laurent S, et al. Pulmonary veno-occlusive disease: Recent progress and current challenges. Respiratory Medicine 104: S23-S32, 2010.

7. Eyries M, Montani D, Girerd B, et al. EIF2AK4 mutations cause pulmonary veno-occlusive disease, a recessive form of pulmonary hypertention. Nat Genet 46: 65-69, 2014.

8. Girerd B, Montani D, Jais X, et al. Genetic counselling in a national referral centre for pulmonary hypertention. Eur Respir J 47: 541-552, 2016

9. Rabiller A, Jais X, Hamid A, et al. Occult alveolar haemorrhage in pulmonary veno-occlusive disease. Eur Respir J 27: 108-113, 2006.

10. Resten A, Maitre S, Humbert M, et al. Pulmonary hypertension: CT of the chest in pulmonary venoocclusive disease. AJR Am J Roentgenol 183: 65-70, 2004.

11. Grosse C, Grosse A. CT findings in diseases associated with pulmonary hypertension: a current review. Radiographics 30: 1753$1777,2010$.

12. Holcomb BW Jr, Loyd JE, Ely EW, et al. Pulmonary venoocclusive disease: a case series and new observations. Chest 118: 1671-1679, 2000.

13. Montani D, Achouh L, Dorfmuller P, et al. Pulmonary venoocclusive disease: clinical, functional, radiologic, and hemodynamic characteristics and outcome of 24 cases comfirmed by histology. Medicine(Baltimore) 87: 220-233, 2008.

14. Galie N, Hoeper MM, Humbert M, et al. Guidelines for the diagnosis and treatment of pulmonary hypertension. Eur Respir J 34: 1219-1263, 2009.

15. Japan Organ Transplant Network. NEWS LETTER 19: 6, 2015.

16. Ogawa A, Miyaji K, Yamadori I, et al. Safety and efficacy of epoprostenol therapy in pulmonary veno-occlusive disease and pulmonary capillary hemangiomatosis. Circ J 76: 1729-1736, 2012.

The Internal Medicine is an Open Access article distributed under the Creative Commons Attribution-NonCommercial-NoDerivatives 4.0 International License. To view the details of this license, please visit (https://creativecommons.org/licenses/ by-nc-nd/4.0/).

(C) 2017 The Japanese Society of Internal Medicine

http://www.naika.or.jp/imonline/index.html 